\title{
Linking Community with Primary Health Care through Peer Support in Swaziland
}

\section{Mats Malqvist}

International Maternal and Child Health, Department of Women's and Children's Health, Uppsala University, Sweden

*Corresponding author: Mats Malqvist, Associate Professor, Uppsala University, Department of Women's and Children's Health, Akademiskasjukhuset, Uppsala, 75185, Sweden, Tel: +26876718152; E-mail: mats.malqvist@kbh.uu.se

Rec date: Sep 26, 2014, Acc date: Nov6, 2014; Pub date: December 16, 2014

Copyright:@ 2014 Malqvist M. This is an open-access article distributed under the terms of the Creative Commons Attribution License, which permits unrestricted use, distribution, and reproduction in any medium, provided the original author and source are credited.

\section{The challenge}

Health care delivery in the continuum of mother and childcare is faced with multiple barriers in low- and middle-income countries and the "inverse care law", which stipulates that the ones in greatest need are the ones least likely to receive adequate care [1], is painfully present. Swaziland is a small country with huge health problems. The country is displaying the world's highest HIV prevalence, with $26 \%$ of the total population and up to $50 \%$ of pregnant women being HIV positive [2]. Furthermore, Swaziland is among the bottom five countries when it comes to improvement in child mortality, with an under-5 mortality rate of 70/1000 live births [3]. Inequities in society are huge, despite being a middle-income country in terms of GDP, more than $60 \%$ of the population lives on less than 1.25 USD a day [4].

Major obstacles to the provision and improvement of maternal and child health in Swaziland are cultural factors and patriarchal gender norms. Limited autonomy of women caused by cultural, economic and administrative structures generate poor conditions for women and children to promote and maintain good health [5]. Polygamous relationships, high unemployment rates with subsequent poverty and malfunctioning governance aggravates the risks for ill health and stands in the way of health promotion and delivery. Hence, there is a need for approaches that could impact on a range of barriers related to societal and cultural norms.

\section{Peer support through community-based Mentor Mothers}

In settings where health systems are failing to deliver care and where cultural and structural constraints are abundant, like in Swaziland, peer support models have been suggested as a possible method for increasing access to the health care system and improving adherence to medical treatment [6]. Peer support serves as a method to advocate for women's and children's rights, empowering its clients to make, and carry through, informed decisions about their own health and life situation.
Since 2012 an outreach project for improved maternal and child health has been running in Matsapha, a semi-urban area outside Swaziland's largest city. The project, called Siphilile, builds on a peer support model developed in Cape Town, South Africa, by an organization called Philani. The primary goal of the Philani model is to improve maternal and child health and survival. The model deploys "Mentor Mothers" in the community and has been shown to improve overall health of its beneficiaries [7]. In practical terms, this includes; the identification of malnourished children through home-based growth monitoring, screening for tuberculosis (TB), encouragement of antenatal clinic attendance and HIV testing, nutritional and dietary counselling, encouragement of breastfeeding, training in sanitation, screening of maternal depression, assistance in gaining access to social assistance and referral to health facilities when necessary.

In October 2014, Currently 32 Mentor Mothers are working for Siphilile in Matsapha, covering a population of about 30000 . The core of this community-based Mentor Mother model is training and supervision. Applicants should be women who have managed to raise children despite harsh conditions and who are role models in their community. The positive deviant model is a theoretical foundation of the Mentor Mother model [8]. The mothers do not have to have any previous health education, but are required to have completed at least twelve years of schooling. Before being officially accepted as Mentor Mothers they undergo a one-month in-house training with strictly defined knowledge and skills assessments. Once a Mentor Mother is accepted, she is under continuous supervision by field coordinators and a standardized reporting system ensures intervention quality.

Broken social relations, unemployment and poverty characterize the population of Matsapha. Of the enrolled clients more than $10 \%$ are teenage mothers and a vulnerable life situation with multiple partners and economic dependence is commonplace. Siphilile does not provide HIV testing, but more than $35 \%$ of the mothers have disclosed a positive HIV status to the Mentor Mothers (Table 1). Stigma of an HIV positive status is still present and a culture of silence is prevailing in the Swazi context [5].

\begin{tabular}{|l|l|}
\hline Enrolled women (n=1032) & $\mathbf{n}$ \\
\hline Still pregnant & $217 / 1032$ \\
\hline Pregnant HIV positive & $73 / 217$ \\
\hline Pregnant on anti-retroviral therapy (Option B+) & $89 / 217$ \\
\hline Pregnant women not attending antenatal care & $12 / 217$ \\
\hline Pregnant teenagers & 273.6 \\
\hline
\end{tabular}


Citation: Malqvist M (2014) Linking Community with Primary Health Care through Peer Support in Swaziland. Primary Health Care 4: 176. doi: $10.4172 / 2167-1079.1000176$

Page 2 of 2

\begin{tabular}{|l|l|l|}
\hline Delivered & $817 / 1032$ & 79.2 \\
\hline Teenage mothers & $71 / 817$ & 8.7 \\
\hline Low birth weight babies & $41 / 817$ & 5.0 \\
\hline HIV positive mothers & $308 / 817$ & 37.7 \\
\hline Infants older than 6 weeks to HIV+ mothers & $280 / 308$ & 90.9 \\
\hline Infants PCR tested at 6 weeks of age & $278 / 280$ & 99.3 \\
\hline HIV positive infants (PCR positive) & $4 / 308$ & 1.3 \\
\hline Enrolled children (n=173) & & 11.0 \\
\hline Severely underweight for age & $19 / 173$ & 21.4 \\
\hline Low birth weight & $37 / 173$ & 43.9 \\
\hline HIV+ mothers & $76 / 173$ & 5.8 \\
\hline HIV+ children & $10 / 173$ & \\
\hline
\end{tabular}

Table 1: Clients enrolled in the Siphilile Mentor Mother program in October $2014(\mathrm{n}=1205)$

\section{Linking community with primary health care}

The Mentor Mothers act as a link between the community and the primary health care through their presence and connection to the local context. Compared to Rural Health Motivators (RHMs), as the usual community health workers are called in Swaziland, the Mentor Mothers have a smaller area of responsibility, are more focused toward a specific patient group, mothers and children, and have a higher level of supervision, training and demand for accountability. This facilitates the possibility of a greater impact on health outcomes and assists the primary health care as its advocates in the community. In Matsapha, the Mentor Mothers collaborate with a local clinic run by Doctors without borders (MSF), which is the main primary health care provider. The collaboration works two ways; the Mentor Mothers can refer their clients to the clinic, and the clinic can utilize the Mentor Mothers in defaulter tracing, given their knowledge about the community and its inhabitants.

In settings like Swaziland, where resources for primary health care are limited and where prevention is key in order to reduce the further spread of HIV and TB there is a need to find new innovative ways to promote good health. To overcome the problems of inconsistent antiretroviral treatment and defaulting $\mathrm{TB}$ treatment there is a need for a community link [6]. To be able to follow up on patients outside the clinic might not be feasible for already overloaded clinic staff, but through task-shifting to Mentor Mothers this link can be sustained. The peer support model developed by Philani in Cape Town, now successfully replicated in a different setting is suggested to be a viable intervention strategy to bridge the gap between community and the health care providers and expand services where governance and resources are poor.

\section{References}

1. Hart JT (1971) The inverse care law. Lancet 1: 405-412.

2. World Health Organization: Global Health Observatory Data Repository (2013) Data on the size of the HIV/AIDS epidemic: prevalence of HIV among adults aged 15-49 (\%) by country.

3. Countdown to 2015: Accountability for maternal, newborn and child survival (2013).

4. World Bank data (2014).

5. Hallonsten G (2012) Not the whole story - The impact of the church, traditional religion and society on the individual and collective perceptions of HIV in Swaziland.

6. Ackerman Gulaid L, Kiragu K (2012) Lessons learnt from promising practices in community engagement for the elimination of new HIV infections in children by 2015 and keeping their mothers alive: summary of a desk review. J Int AIDS Soc 15 Suppl 2: 17390.

7. le Roux IM, Tomlinson M, Harwood JM, O'Connor MJ, Worthman CM, et al. (2013) Outcomes of home visits for pregnant mothers and their infants: a cluster randomized controlled trial. AIDS 27: 1461-1471.

8. Schooley J, Morales L (2007) Learning from the community to improve maternal-child health and nutrition: the Positive Deviance/Hearth approach. J Midwifery Womens Health 52: 376-383. 